\title{
Opinion
}

Damon P. Coppola* and Benjamin J. Ryan

\section{Color-coding for COVID-19 Management: An Idea Whose Time has Come}

https://doi.org/10.1515/jhsem-2020-0021

Received April 11, 2020; accepted April 14, 2020

Abstract: COVID-19 has awakened the country to a heightened state of daily, ongoing readiness for pandemic risk. Following the 9/11 terrorist attacks, the U.S. Government released a color-coded alert system to inform the public and support appropriate response, but the system was of little utility to most people. In the context of pandemic, where significant modifications to daily life are required and which change with local and regional transmission risk, the time for a color-coded alert system may have finally come

Keywords: COVID-19, pandemic, epidemic

Like 9/11 was to terrorism, it took COVID-19 to make Americans understand on a societal level the risk posed by pandemics.

Al Qaeda terrorists woke the country to a heightened state of daily, ongoing readiness, much like is happening experiencing today with the ongoing coronavirus pandemic. At the time, the newly-formed Department of Homeland Security released a color-coded, incremental alert system. With it, it was proposed, individuals, businesses, and governments could act or react in informed and appropriate ways according to incremental levels of threat.

While innovative, this system was very rarely used to issue alerts. It was replaced in 2011 after reviews found it of very limited utility for informing members of the public about preparedness for and response to terrorism risk. Today, faced with a very different threat that affects all people, and all organizations, at all times, and that does so in a direct and profound way requiring a scope of actions broader than anything this country has seen - such a system's time may have finally come.

*Corresponding author: Damon P. Coppola, MEM, ARM, Shoreline Risk LLC, McLean, VA, USA, E-mail: dcoppola@shorelinerisk.com

Benjamin J. Ryan, Ph.D., MPH: Environmental Science, Baylor University, Waco, TX, USA, E-mail: benjamin_ryan@baylor.edu 


\section{HOMELAND SELURITY} ADVISDRY SYSTEM

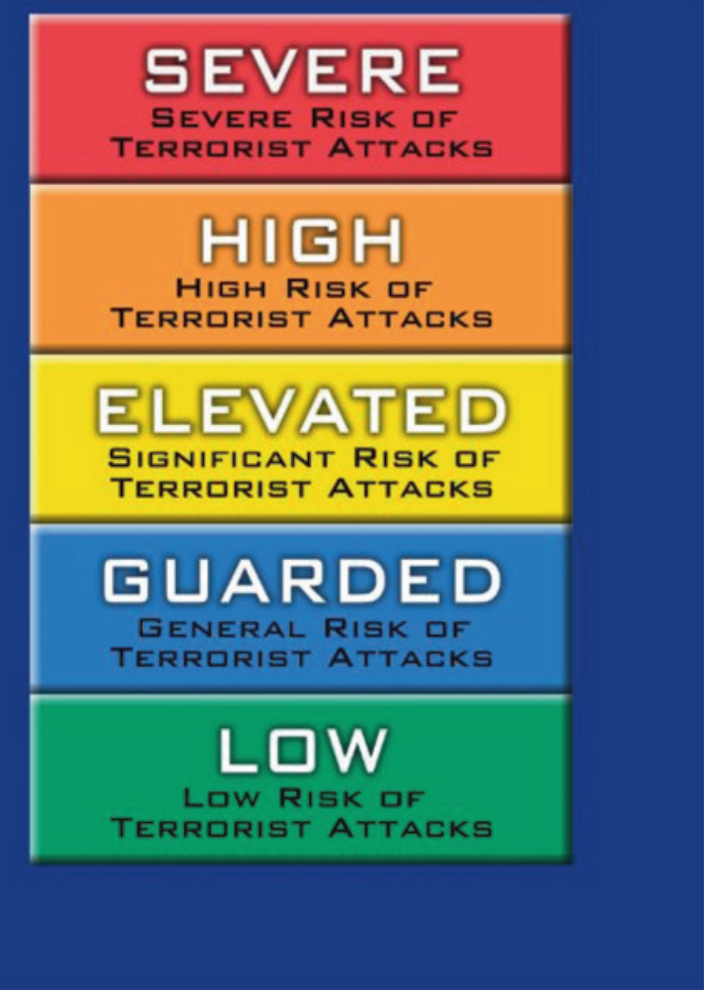

Figure 1: The color-coded and 'always on' Homeland Security Advisory System, which was replaced in 2011 by the alert-based National Terrorism Advisory System.

The Homeland Security Advisory System (HSAS) was the product of a Presidential Directive (HSPD-3). It was meant to provide a comprehensive and effective means to disseminate information on day-to-day terrorism risk to governments at all levels and to the American public. Announcements were made to indicate when movements occurred up or down the color-coded series of incremental "Threat Conditions". At each level, governments, business, and the public were given information on suggested protective measures that could be taken (see Figure 1).

Connecting a system like the HSAS to every citizen was a bridge too far. With the rarity of actual attacks that occurred, and the fact that most people felt little sense 
that their actions could make a difference, the collective national attention span waned - especially in light of the hundreds of naturally-induced disasters that were continuing to strike throughout the nation. With release of the subsequent the National Terrorism Advisory System (NTAS), no longer were there color-codes, operational levels, and for most people, knowledge that the program even existed.

Our past brushes with pandemic, like those of pre-9/11 attacks, were newsworthy but remained distant from most communities and often abstract or even outlandish at times. Ebola and SARS infected and in some cases killed people in America, but there was an air of sensationalism about these events that ultimately never materialized for most people (and for no part of America did it have the psychological or social impact that these pathogens had in Africa and Asia, respectively). As a society, Americans became nonchalant about a risk that, relative to other threats, regularly causes remarkable suffering and death. Case in point - COVID-19 with its recent predicted fatality toll is at worst just over twice what we see on a flu season of elevated activity. In 2017 alone, we saw 60,000 deaths in the US and 650,000 globally. Even in average years we expect upwards of 30,000 domestic deaths and 200,000 to 300,000 deaths worldwide.

This is all to say that while life with COVID-19 has been called our 'new normal', pandemic health risk has always been with us. Let's compare apples to apples - pandemic risk in the form of Influenza A and B has always, every year, caused more death and destruction than even the most ambitious terrorist organizations could hope to achieve in a dozen lifetimes.

Yet aside from annual flu shots, mandated hand washing in schools, and the occasional Purell station in an office building lobby, individuals have faced very little personal responsibility to support our national public health.

Until, now, that is. We are facing the greatest national sacrifice we've been asked to make since the Greatest Generation brought us through the hardships of WWII. And in doing so, we are beginning to ask ourselves, and our leaders: when will this end? What will it look like when it does? And what can we do?

Americans are awakening to the bitter reality that the COVID-19 pandemic may not be resolved by summer and perhaps not for months or even years thereafter. There will be no sense of safety to emerge to that looks or feels like the one that was left behind. Even if a vaccine or effective treatment for COVID-19 is developed, the potential for another pathogen of similar or even greater human and societal impact can no longer be denied.

In light of this, emerging from lockdown will not be akin to flicking an 'On/Off' switch where we just go back to life as before. There will be modifications to community function, to social interaction, and to various social services that enable us to better balance life safety with viable societal function. Each community will differ greatly in terms of their day-to-day threat, their capacity to manage a change in 


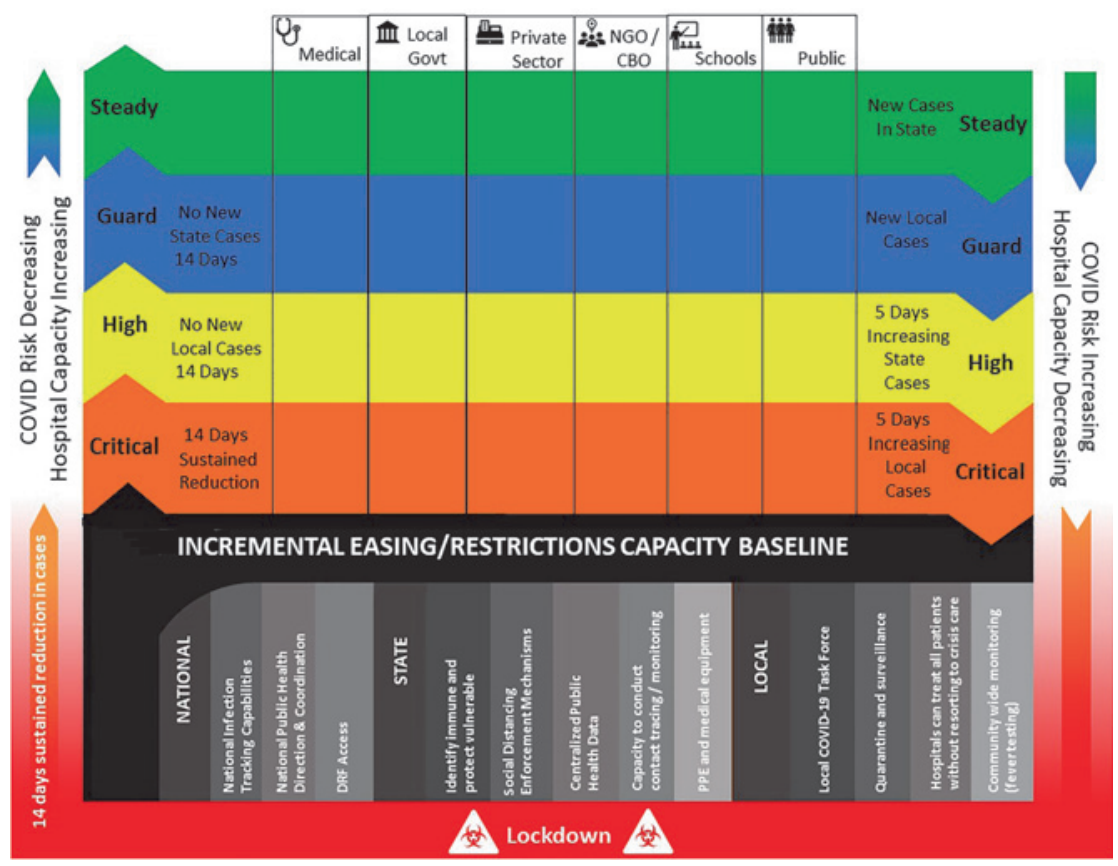

Figure 2: Concept for a new Community Protection Advisory System.

infection cases and outlooks, and the unique demographic characteristics that define how significant pandemic threats are in relation to the many other risks we face.

There are calls for a framework that allows for unique action based on locationspecific risk, vulnerability, and coping capacity. The White House has provided guidelines to reopen the country, but communities and individuals will need something that indicates actions both recommended and required with little more than a glance. Individuals will need to know whether or not to wear masks, to keep physical distance from others, or to avoid the outdoors altogether. Businesses will need to know whether it is safe to open, and if so, what measures are required to protect their employees and customers. And government administrators will need guidance on whether or not to permit concerts or festivals, to congregate children in classrooms, or to increase capacities to manage medical and social services, for example.

Perhaps these defined sets of action correspond to different colors, on a standardized chart that we can all come to be familiar with. A Community Protection Advisory System (see Figure 2). The time for such a color-coded alert system has finally come.

Article Note: A policy brief on the proposed framework can be found at: https://bit.ly/3a44GNb 